\title{
Clinical characteristics of women with major depression who suffered sexual abuse in childhood
}

\author{
José A. Ortiz-Guzmán, ${ }^{1}$ María C. Ibarra-Alcantar, ${ }^{1,2}$ Francisco J. Alvarado-Cruz, ${ }^{1}$ \\ Hermelinda Graciano-Morales ${ }^{1}$ and Alejandro Jiménez-Genchi ${ }^{3}$ \\ ${ }^{1}$ Mental Health Community Center; ${ }^{2}$ Hospital Psiquiátrico Fray Bernardino Álvarez; ${ }^{3}$ Secretaría de Salud, Instituto Nacional de Psiquiatría Ramón
} de la Fuente. Ciudad de México, Mexico

\begin{abstract}
Introduction: Even when child sexual abuse (CSA) is a risk factor for the development of major depression in adult women, data on the clinical features associated with this traumatic event are scarce. Objective: To assess the history of CSA and its association with some clinical manifestations in women with major depression. Method: Seventy-one adult women with major depression were selected in a community-based mental health center. They were assessed with the Mini International Neuropsychiatric Interview, the Beck Depression Inventory, the Social Adaptation Self-evaluation Scale, and childhood physical maltreatment and child sexual abuse indices. Results: Some form of CSA had been suffered by 53.5\%. There were no significant differences in age, level of education, depressive symptoms, social adaptation or physical maltreatment during childhood between the women with or without a history of CSA, only a higher frequency of comorbid social anxiety disorder (26\% versus $6 \%$ ) and a higher proportion of suicide risk (68\% versus $45.4 \%$ ) differentiated the groups. Conclusion: Few characteristics distinguish women with major depression with a history of CSA; however, the prognosis and therapeutic implications of a higher suicide risk underscore the importance of systematically investigating the history of CSA among women with major depression.
\end{abstract}

KEY WORDS: Major depression. Child sexual abuse. Physical maltreatment. Suicide risk. Social functioning.

\section{Introduction}

Childhood sexual abuse (CSA) is one of the most traumatic adverse experiences and with greater impact on individual emotional development. ${ }^{1-3}$

According to a review of international epidemiology of this phenomenon, towards the end of the $20^{\text {th }}$ century, between 7 and $36 \%$ of women had suffered CSA ${ }^{1}$ specifically, 1 out of every 5 women was estimated to have been the victim of CSA in the United States. In Mexico, the 2003 National Survey on Violence against Women found a prevalence of $7.3 \%$ in primary and secondary care services female users. ${ }^{2}$ In turn, the 2006 Survey on Child Maltreatment and Associated Factors carried out in adolescents from Baja California, Sonora, Tlaxcala and Yucatán, reported a prevalence of sexual abuse between 3.5 and $9.1 \%$ in the female population. $^{3}$

A considerable number of studies and several meta-analytic reviews have consistently documented that CSA is associated with the development of psychiatric disorders in adulthood. ${ }^{4}$ This effect appears to be particularly more pronounced in women, predisposing them to a higher number of psychiatric disorders in comparison with men. ${ }^{5}$ The most widely studied association has been the one existing between CSA and major depressive disorder, with the former being identified as a strong risk factor for the development of the latter, even with some causal effect being attributed to it. 6,7

But not only is CSA contribution to depression causality is important, but it can also be relevant to the configuration of depressive episodes' symptomatic
Correspondence: Alejandro Jiménez-Genchi E-mail: jimalex@imp.edu.mx
Date of reception: 25-01-2017

Date of acceptance: 06-02-2018

DOI://dx.doi.org/10.24875/GMM.M18000145
Gac Med Mex. 2018;154:239-244

Contents available at PubMed www.gacetamedicademexico.com 
profiles, although information is more limited in this issue. Women with depression and a history of CSA have been found to develop the first depressive episode at an earlier age, to exhibit more self-harm, suicidal and impulsive behaviors, ${ }^{8-10}$ more comorbid psychiatric disorders ${ }^{11}$ and to be at higher risk for suffering physical and sexual abuse in adulthood. ${ }^{10}$

Only few studies have assessed psychiatric comorbidity, social functioning and associations with other types of abuse in women with major depression and a history of CSA. When the relationship with clinical characteristics such as the severity of depressive symptoms has been investigated, poorly consistent results have been obtained. By virtue of the above, the purpose of the present work was to assess the history of childhood sexual abuse and its association with some clinical manifestations, such as the severity of depressive symptoms, suicide risk, social functioning and history of physical abuse in women with major depressive disorder.

\section{Method}

\section{Participants}

A non-probabilistic convenience sample of the population that sought psychiatric care at the Cuauhtémoc Mental Health Community Center of Mexico City between March 4 and August 31, 2005 was selected. Only literate women between 18 and 65 years of age who at admission clinical evaluation were diagnosed with major depressive disorder (according to DSM-IV criteria) and who had not received pharmacological or psychotherapeutic treatment within the previous 3 months were invited to participate. After an explanation of the characteristics and purpose of the study, they were asked for written informed consent.

\section{Procedure}

All patients were applied the Mini-International Neuropsychiatric Interview (MINI) ${ }^{12}$ with the purpose to confirm the main diagnosis and document psychiatric comorbidity. In addition, an information form was used to record each participant's sociodemographic data and other clinical characteristics.

The interviews were conducted by psychiatrists with clinical experience and training on administration of the MINI instrument. The research project was approved by the institutional review board. After concluding the diagnostic interview, the participants completed a series of evaluation instruments.

\section{Instruments}

Beck's Depression Inventory $(\mathrm{BDI})^{13}$ is a self-administered instrument that is widely used in depression research. It consists of 21 items on different depressive symptoms, with 4 answer options for each item with values ranging from 0 to 3 . When item scores are added up, an overall depression severity measurement is obtained, with higher scores corresponding to higher severity.

The Childhood Sexual Abuse Index (CSAI) was developed as part of the investigation; details of the procedure have been previously described. ${ }^{14}$ Briefly, three researchers created an item bank with the purpose to investigate a wide variety of maltreatment experiences suffered in childhood. Four clinicians who were experts in the care of abuse survivors acted as judges and classified the items in several abuse categories. Items considered by at least three of judges as sexualabuse were employed to construct the CSAI.

The questionnaire, which is presented in the appendix, is composed of 8 items that investigate the history and characteristics of different childhood sexual abuse experiences (subject's age, number of occasions it occurred, relationship with and age of the abuse perpetrator). The values for each item were obtained from the number of occasions the subject recorded having suffered the abuse in question. Some of its psychometric properties were assessed in a sample of 115 women. The correlation coefficients between each item and their total addition were significant $(0.73,0.63,0.59,0.76,0.77,0.84$, 0.47 and 0.28 , respectively; $p<0.01$ ). The reliability coefficient in said sample was 0.80 , while in the participants of this study it was 0.78 . In this research, a categorical measurement of sexual abuse was employed, where its presence was defined as a score higher than zero.

The Childhood Physical Abuse Index (CPAl) was also constructed as part of the research and in parallel to the CSAI. It has a self-administered format and is composed of 5 items that investigate the frequency the subject was beaten with by her parents or legal guardian when she was between 3 and 17 years old. The answer options are never, sometimes, frequently and almost always, whose values are 0, 1, 2 and 3, respectively. The sum of the scores for each item provides an overall score for physical abuse. In a clinical sample of women with major depression or dysthymia, the CPAI showed a reliability coefficient of $0.88 .^{14}$ In this study population, reliability was also satisfactory $(0.90)$.

Suicide risk was determined by means of MINI's corresponding module..$^{12}$ This section is comprised by 
Table 1. Sexual abuse perpetrator relationship with the survivor

\begin{tabular}{|c|c|c|c|c|c|c|c|c|c|}
\hline \multirow[t]{2}{*}{ Abusive behavior } & \multirow[t]{2}{*}{$\mathbf{n}$} & \multicolumn{7}{|c|}{$(\%)$} & \multirow[b]{2}{*}{ Stranger } \\
\hline & & Father & Stepfather & Brother & Uncle & Cousin & Friend & Neighbor & \\
\hline Taking clothes off & 23 & 17.3 & - & - & 17.3 & 30.4 & 4.3 & 8.6 & 21.7 \\
\hline Sexual touching & 24 & 12.5 & 4.1 & - & 29.1 & 29.1 & - & 4.1 & 20.3 \\
\hline Touching the aggressor* & 17 & 11.7 & - & 5.8 & 23.5 & 17.6 & - & 5.8 & 29.4 \\
\hline Giving kisses & 10 & 10 & 10 & 20 & 10 & 20 & - & - & () 30 \\
\hline Being kissed & 13 & 7.7 & 7.7 & - & 23 & 23 & - & 7.7 & 30.7 \\
\hline Rubbing & 21 & 9.5 & 9.5 & 4.7 & 14.2 & 33.3 & - & - & 28.5 \\
\hline Attempted intercourse ${ }^{*}$ & 15 & 26.6 & - & - & 13.3 & 20 & - & - & 26.6 \\
\hline Penetration* & 11 & - & - & - & 27.2 & 9.1 & - & - & 54.5 \\
\hline
\end{tabular}

${ }^{*}$ For some aggressors, relationship was not identified and therefore the percentages are lower than 100.

6 questions about the presence of death wishes, selfharm, suicidal ideation, suicide plans and suicide attempts in the previous month, as well as throughout life. Answer options are yes and no, with 1, 2, 6, 10, 10 and 4 points corresponding to affirmative answers; when these values are added up, an overall score is obtained that classifies suicide risk as minor (1-5 points), moderate (6-9 points) and high ( $\geq 10$ points). In this study, a dichotomous definition was used, with the presence of suicide risk been considered when overall score was 1 or higher.

The Social Adaptation Self-evaluation Scale (SASS) is comprised by 21 items that assess behavior and social motivation in the areas of work and leisure, family and extra-family relationships, intellectual interests, satisfaction with roles and patient self-perception on his/her ability to manage and control his/her environment. ${ }^{15}$ Each answer has a value ranging from 0 to 3 , which correspond to minimal and maximal social adjustment; total score ranges from 0 to 60 , indicating higher social adjustment as the score increases. It has been reported to possess an acceptable reliability (Cronbach's $\alpha=0.74$ ), appropriate temporal stability and to be sensitive to change. The Spanish version has shown satisfactory psychometric properties as well. ${ }^{16}$

\section{Analysis}

The results are described with means and standard deviations, as appropriate. t-tests were used to compare depressive symptomatology, childhood physical abuse and social adaptation scores between women with CSA-positive versus negative history; suicide risk was compared with the chi-square test or Fisher's exact test. A $p$-value $<0.05$ was established to be significant.

\section{Results}

Seventy-six women were assessed, out of which 5 were excluded because they had a previous history of manic or hypomanic episodes. Of the 71 participants included in the study, $53.5 \%$ reported having suffered some form of CSA. The different forms of sexual abuse experienced by the patients, as well as the relationship with the perpetrator, are presented in table 1; $81.5 \%$ $(n=31)$ of the women with CSA suffered more than one form of abuse between 3 and 17 years of age, with a mean of $8.3 \pm 2.2$ years of age.

When demographic characteristics such as age and level of education were compared, no significant differences were found between women with and without a history of CSA. Neither were differences observed in the severity of depressive symptoms, the degree of psychosocial adjustment and the severity of physical abuse. Only social anxiety disorder and the presence of suicide risk were significantly more common in women with a CSA-positive history (Table 2).

\section{Discussion}

In this sample of women with major depression attending a mental health community center to receive care, we found that half of them had been the victims of some type of sexual abuse in their childhood, which in addition was associated with higher comorbidity with social anxiety disorder and suicide risk.

The proportion of women with CSA is notoriously higher than that which has been found in female users of primary ${ }^{17}$ and secondary care centers $(7 \text { to } 21 \%)^{2}$ and in the general population (3.5 to $9.1 \%),{ }^{3}$ and it is even higher than the $23-30 \%$ rates reported in other studies with this 
Table 2. Demographic and clinical characteristics of the sample

\begin{tabular}{|c|c|c|c|c|c|c|}
\hline & \multicolumn{2}{|c|}{$\begin{array}{c}\text { No sexual } \\
\text { abuse } \\
(n=33)\end{array}$} & \multicolumn{2}{|c|}{$\begin{array}{c}\text { With sexual } \\
\text { abuse } \\
(n=38)\end{array}$} & \multirow[t]{2}{*}{$\begin{array}{c}t \\
\text { (df 69) }\end{array}$} & \multirow[t]{2}{*}{$p$} \\
\hline & Mean & SD & Mean & SD & & \\
\hline Age (years) & 37.8 & 11.8 & 36.0 & 9.8 & 0.67 & 0.50 \\
\hline Level of education (years) & 10.1 & 3.6 & 10.0 & 3.1 & 0.22 & 0.82 \\
\hline $\begin{array}{l}\text { Beck's depression } \\
\text { inventory }\end{array}$ & 29.8 & 8.3 & 31.3 & 9.9 & -0.68 & 0.49 \\
\hline Social adaptation & 31.0 & 8.9 & 30.7 & 9.2 & 0.16 & 0.87 \\
\hline \multirow[t]{2}{*}{ Physical abuse } & 3.6 & 4.5 & 5.5 & 4.4 & -1.7 & 0.08 \\
\hline & $\mathrm{n}$ & $\%$ & $\mathrm{n}$ & $\%$ & $\begin{array}{c}\chi^{2} \\
\text { (df 1) }\end{array}$ & $p$ \\
\hline Suicide risk & 15 & 45.4 & 26 & 68 & 3.8 & 0.04 \\
\hline Panic disorder & 8 & 24.2 & 13 & 34.2 & 0.84 & 0.25 \\
\hline Agoraphobia & 4 & 12.1 & 6 & 15.7 & $\S$ & 0.46 \\
\hline Social anxiety disorder & 2 & 6.0 & 9 & 23.6 & 4.1 & 0.04 \\
\hline $\begin{array}{l}\text { Obsessive } \\
\text { compulsive-disorder }\end{array}$ & 1 & 3.0 & 0 & 0 & $\S$ & 0.46 \\
\hline $\begin{array}{l}\text { Post-traumatic stress } \\
\text { disorder }\end{array}$ & 1 & 3.0 & 1 & 2.6 & $\S$ & 0.71 \\
\hline Alcohol abuse & 0 & 0 & 2 & 5.2 & $\S$ & 0.28 \\
\hline Anorexia nervosa & 0 & 0 & 1 & 2.6 & $\S$ & 0.53 \\
\hline Bulimia & 3 & 9.0 & 3 & 7.8 & $\S$ & 0.59 \\
\hline $\begin{array}{l}\text { Generalized anxiety } \\
\text { disorder }\end{array}$ & 15 & 45.4 & 15 & 39.4 & 0.25 & 0.39 \\
\hline
\end{tabular}

SFisher's exact test. $\mathrm{df}=$ degrees of freedom.

clinical population. ${ }^{9-11}$ The explanations for this difference include the study population, i.e., a clinical sample of women with one of the psychiatric disorders most commonly associated with a history of sexual abuse, ${ }^{7}$ and together with this characteristic, the definition of sexual abuse that was employed. Studies that have defined it as intercourse (penetration) against the victim's will have reported the lowest figures ${ }^{2,17}(7$ to $11 \%)$, while the proportions increase (21-29.4\%) when other forms of sexual contact are included (e.g., sexual touching); ${ }^{10,11,17}$ furthermore, some studies have considered sexual contact as sexual abuse only when the perpetrator is at least 5 years older than the victim, ${ }^{3,11}$ which also can give rise to a reduction in the figures.

This way, the elevated proportion of women with a history of CSA that we found may be due to the fact that the CSA definition we used is more inclusive as it contemplates a larger variety of sexual contact forms without an age criterion for the abuse perpetrator being established. On the other hand, it should be noted that this finding is consistent with evidence that indicates higher vulnerability for suffering major depression among subjects with a history of CSA. ${ }^{7}$

Although there is little doubt about the contribution, at least partial, of sexual abuse to the subsequent appearance of depressive episodes, $, 6,7$ our results suggest that there are only few clinical characteristics that differentiate women with depression and a history of sexual abuse from those who didn't suffer it. As regards depressive symptoms, we found no significant differences between groups based on the history of CSA. It should be pointed out that available studies have obtained mixed results. Gladstone et al., ${ }^{9}$ in an initial study, found that women with major depression who had suffered CSA showed BDI higher scores, but not in clinical appraisals made with Hamilton depression rating scale (HAM-D), whereas in a second report ${ }^{10}$ by the same group of researchers with a different sample, no significant differences were found in HAM-D or in a 4-point scale (no depression to severe depression).

Neither did Zlotnick et al. ${ }^{11}$ find significant differences in depressive symptoms severity in a sample predominantly comprised by women (85\%). In contrast, Gamble et al., ${ }^{18}$ also with HAM-D, identified that patients $>50$ years of age with major depression and a history of CSA showed higher scores, although this investigation included a balanced sample of men and women and gender contribution was not analyzed.

The inconsistency of results between different studies does not appear to be driven by the way in which sexual abuse was measured, since even though different instruments were employed, all agree in defining sexual abuse as any unwanted experience that involved physical contact. Hence, this series of findings suggests that, while traumatic sexual experience favors the appearance of major depressive disorder, its influence on depressive symptoms severity during the episodes appears to be weak.

Regarding the presence of other comorbid psychiatric disorders, we found more prevalence of social anxiety disorder among women with a history of CSA. In this regard, available information is also variable. For example, one study identified a higher prevalence of panic disorder as comorbidity, ${ }^{10}$ while in other post-traumatic stress disorder was more frequently recorded.11 This variability might be due to the fact that sexual abuse per se increases psychopathology risk in general. Although particularities of the clinical populations of each one of these investigations might also be influencing, since history of CSA in the general population has been 
associated with a significant increase in the risk for developing precisely these three disorders (panic disorder, post-traumatic stress disorder and social anxiety disorder) and only in women. ${ }^{5}$ This indicates that assessing for the comorbid presence of at least these three psychiatric entities is necessary in women with depression and a history of CSA.

Two studies have evaluated overall functioning in CSA-survivor women with depression and, again, the results are mixed. Both used the Global Assessment of Functioning scale: one found that women with a history of CSA had a significantly lower functioning, ${ }^{9}$ which was not reproduced in the other. ${ }^{11}$

As for social functioning, Mullen et al. ${ }^{19}$ had pointed out that childhood sexual abuse increased vulnerability to the development of difficulties in social, interpersonal and sexual functioning in women's adult life. However, only one study ${ }^{11}$ has assessed social functioning in CSA-survivor women with depression. Our results are consistent with that investigation. since no significant differences in social functioning were found. According to the proposed normative values, the SASS scores observed in either group of women are below normal range (32-52 points), which corresponds to a profile characterized by few extra-family relationships, communication difficulties, little interest and pleasure in activities that are carried out and difficulties to become independent, ${ }^{15}$ these scores are similar to those reported by subjects with major depression prior to receiving pharmacological treatment.

It is difficult for this lack of differences in social functioning to be explained, in part due to the multiple variables that determine it. However, it is possible for sexual abuse to have an effect only on particular components of social behavior. In this sense are Gamble et al. ${ }^{20}$ findings, who recently reported that CSA-survivor women who receive psychotherapy derive little benefit in the intimate and immediate family relationships domain, in comparison with other social functioning domains, such as work, pleasant activities with friends and extra-family relationships. It is also possible for the form in which the subject reacts to the experience of abuse to be what influences on social functioning, just as Lien and Bouewdy ${ }^{21}$ indicated when they identified that only the degree at which subjects felt responsible for the abuse significantly predicted social functioning, in comparison with other variables such as CSA frequency, search for help to cope with the experience and abuse in adult relationships. CSA effects on social functioning is an area that most certainly requires further investigation.
Besides higher comorbidity with social anxiety disorder, only suicide risk differentiated CSA-surviving women from those who did not suffer such an experience. This result is consistent with findings in previous studies, ${ }^{10,11}$ where women with depression and a history of CSA have been described to show more suicide attempts and self-harm behaviors. In the longitudinal study of the Zurich sample, ${ }^{22}$ Angst et al. found that, among women, childhood sexual abuse was one of the most powerful predictors of future presence of suicide attempts $(\mathrm{OR}=7.9)$. Moreover, a recent systematic review on the subject indicates that sexual abuse confers significant risk for developing suicidal behavior or non-suicidal self-harm behaviors. ${ }^{23}$ However, this is an unspecific effect that is difficult to isolate from other variables that commonly coexist with sexual abuse and that are also associated with higher suicide risk, such as other forms of child abuse, adverse family environment and borderline personality disorder, among others. Our findings agree with this point of view, since women with a history of CSA were also detected to have suffered more physical abuse in childhood, although the difference was not significant.

Identifying that a CSA history in women with major depression is associated with higher suicide risk is not a minor finding, since it can have therapeutic implications. Therefore, assessment for a history of childhood sexual abuse should be systematically carried out in women with major depression.

This study shows some limitations that must be considered when interpreting the results. Sample characteristics such as the number of participants, gender and convenience sampling in a primary care institution limit the generalization of results to other populations. Another limitation is that it is a cross-sectional study, and therefore the results correspond only to the moment of assessment and causal inferences cannot be made, as for example, between a history of childhood sexual abuse and suicide risk. It should also be taken into account that investigation about information of an individual's past is subjected to recall bias and that, cognitively speaking, individuals with depression tend to evoke negative memories more often. Nevertheless, recall of emotional experiences has also been observed to be more reliable in periods when the mood is consistent with these memories' emotional content. ${ }^{24}$ In this same line of thought, we must recognize that obtaining clinical information by means of self-report can lead to underreporting, particularly as regards childhood sexual abuse, since this is an embarrassing issue for the 
subject, ${ }^{25}$ although this also occurs at similar proportions with other formats such as interviews, ${ }^{26}$ with which there is consistency. ${ }^{27}$

\section{References}

1. Finkelhor D. The international epidemiology of child sexual abuse. Child Abuse Negl. 1994;18:409-417.

2. Rivera-Rivera $L$, Allen B, Chávez-Ayala R, Avila-Burgos $L$. Abuso físico y sexual durante la niñez y revictimización de las mujeres mexicanas durante la edad adulta. Salud Publica Mex. 2006;48(Supl. 2):S268-S278.

3. Villatoro-Velázquez J, Quiroz-Del-Valle N, Gutiérrez-López ML, Díaz-Santos M, Amador-Buenabad N. ¿Cómo educamos a nuestros/as hijos/as? Encuesta de Maltrato Infantil y Factores Asociados 2006. México: Instituto Nacional de las Mujeres/Instituto Nacional de Psiquiatría Ramón de la Fuente Muñiz; 2006.

4. Chen LP, Murad MH, Paras ML, Colbenson KM, Sattler AL, Goranson EN, et al. Sexual abuse and lifetime diagnosis of psychiatric disorders: systematic review and meta-analysis. Mayo Clin Proc. 2010;85:618-629.

5. Molnar BE, Buka SL, Kessler RC. Child sexual abuse and subsequent psychopathology: results from the National Comorbidity Survey. Am J Public Health. 2001;91:753-760.

6. Kendler KS, Aggen SH. Clarifying the causal relationship in women between childhood sexual abuse and lifetime major depression. Psychological Med. 2014;44:1213-1221.

7. Maniglio R. Child sexual abuse in the etiology of depression: a systematic review of reviews. Depression Anxiety. 2010;27:631-642.

8. Boudewyn AC, Liem JH. Childhood sexual abuse as a precursor to depression and self-destructive behavior in adulthood. J Traumatic Stress. 1995;8:445-459.

9. Gladstone G, Parker G, Wilhelm K, Mitchell PB, Austin MP. Characteristics of depressed patients who report childhood sexual abuse. Am J Psychiatry. 1999;156:431-437.

10. Gladstone GL, Parker GB, Mitchell PB, Malhi GS, Wilhelm K, Austin MP. Implications of childhood trauma for depressed women: an analysis of pathways from childhood sexual abuse to deliberate self-harm and revictimization. Am J Psychiatry. 2004;161:1417-1425.

11. Zlotnick C, Mattia J, Zimmerman M. Clinical features of survivors of sexual abuse with major depression. Child Abuse Negl. 2001;25:357-367.

12. Sheehan DV, Lecrubier Y, Sheehan KH, Amorin P, Janavs J, Weiller E, et al. The MINI-International Neuropsychiatric Interview (MINI): the development and validation of a structured diagnostic interview for DSM-IV and ICD-10. J Clin Psychiatry. 1998;59(Suppl 20):22-23.
13. Beck AT, Steer RA. Beck Depression Inventory Manual. EE. UU.: Psychological Corporation; 1993.

14. Ibarra-Alcantar MC, Ortiz-Guzmán JA, Alvarado-Cruz FJ, Graciano-Morales $\mathrm{H}$, Jiménez-Genchi $\mathrm{A}$. Correlatos del maltrato físico en la infancia en mujeres adultas con trastorno distímico o depresión mayor. Salud Mental. 2010;33:317-324

15. Bosc M, Dubini A, Polin V. Development and validation of a social functioning scale, the Social Adaptation Self-evaluation Scale. European Neuropsychopharmacol. 1997;7 (Suppl 1):S57-S70.

16. Bobes J, González MP, Bascarán MT, Corominas A, Adan A, Sánchez J, et al. Validación de la versión española de la Escala de Adaptación Social en pacientes depresivos. Actas Esp Psiquiatr. 1999;27:71-80.

17. Ramos-Lira L, Saltijeral-Méndez MT, Romero-Mendoza M, Caballero-Gutiérrez MA, Martínez-Vélez NA. Violencia sexual y problemas asociados en una muestra de usuarias de un centro de salud. Salud Publica Mex. 2001;43:182-191.

18. Gamble SA, Talbot NL, Duberstein PR, Conner KR, Franus N, Beckman AM, et al. Childhood sexual abuse and depressive symptom severity: the role of neuroticism. J Nerv Ment Dis. 2006;194:382-385.

19. Mullen PE, Martin JL, Anderson JC, Romans SE, Herbison GP. The effect of child sexual abuse on social, interpersonal and sexual function in adult life. Br J Psychiatry. 1994;165:35-47.

20. Gamble SA, Smith PN, Poleshuck EL, He H, Talbot NL. Domain-specific social functioning improvements during treatment of depressed women with histories of childhood sexual abuse. J Affect Disord. 2011;130: 478-482.

21. Liem JH, Boudewyin AC. Contextualizing the effects of childhood sexual abuse on adult self and social functioning: an attachment theory perspective. Child Abuse Negl. 1999;23:1141-1157.

22. Angst J, Hengartner MP, Rogers J, Schnyder U, Steinhausen HC, Adjacic-Gross V, et al. Suicidality in the prospective Zurich study: prevalence, risk factors and gender. Eur Arch Psychiatry Clin Neurosic. 2014;264: 557-565.

23. Maniglio $R$. The role of child sexual abuse in the etiology of suicide and non-suicidal self-injury. Acta Psychiatr Scand. 2011;124:30-41.

24. Ellis HC, Moore BA. Mood and memory. En: Dalgleish T, Power MJ, eds. Handbook of cognition and emotion. EE. UU.: John Wiley \& Sons; 1999.

25. Henry B, Moffitt TE, Caspi A, Langley J, Silva PA. On the "remembrance of things past": a longitudinal evaluation of the retrospective method. Psychol Assess. 1994;6:92-101.

26. Williams LM. Recall of childhood trauma: a prospective study of women's memories of child sexual abuse. J Consult Clin Psychol. 1994; 62:1167-1176.

27. Fink LA, Bernstein D, Handelsman L, Foote J, Lovejoy M. Initial reliability and validity of the childhood trauma interview: a new multidimensional measure of childhood interpersonal trauma. Am J Psychiatry. 1995;152:1329-1335.

\section{Appendix}

Childhood Sexual Abuse Index

When you were between 3 and 17 years of age, did anyone induce to do any of the following things?

\section{No Yes}

\begin{tabular}{llll}
\hline How old & How many & What was your & How old was this \\
were you? & $\begin{array}{l}\text { times did it } \\
\text { occur? }\end{array}$ & relationship with this & person? \\
& person? &
\end{tabular}

1. Taking your or his clothes off

2. This person touching you

3. You touching this person

4. Giving kisses

5. Receiving kisses

6. Rubbing

7. Attempted to have intercourse

8. Had intercourse (penetration) 